\title{
Societal Institutions and Work and Family Gender-Role Attitudes
}

\author{
Lisa T. Stickney ${ }^{1}$ and Alison M. Konrad ${ }^{2}$ \\ ${ }^{1}$ Merrick School of Business, University of Baltimore, Baltimore, Maryland, USA \\ ${ }^{2}$ Richard Ivey School of Business, The University of Western Ontario, London, Ontario, Canada
}

\begin{abstract}
We examine associations between societal-level policies and gender-role attitudes using nationally representative International Social Survey Program (ISSP) data sets from 14 countries in 1994 and 2002. Hierarchical linear modeling (HLM) findings indicated that tax policies favoring dual-earner families were associated with greater egalitarianism in gender-role attitudes, while the relationship between parental leave times and individual gender-role attitudes was curvilinear in 2002. Low and high parental leave times were associated with traditionalism in gender-role attitude, while mid-length leaves were associated with egalitarianism. The findings support an institutional perspective on gender-role attitudes and suggest that public policies have sufficient impact on people's interests and experiences to influence their gender-role views. Organization Management Journal, 9: 236-246, 2012. doi: 10.1080/15416518.2012.738528
\end{abstract} Keywords $\begin{aligned} & \text { gender-role attitudes; social policies; institutional } \\ & \text { perspective }\end{aligned}$

Extensive research has documented that over time, both men and women have become more egalitarian (less traditional) in their gender-role attitudes (Ciabattari, 2001; Fan \& Marini, 2000; Loo \& Thorpe, 1998; Lye \& Waldron, 1997; Wu \& Baer, 1996). Gender-role attitudes are beliefs regarding appropriate activities and responsibilities for women and men in households and in society (Stickney \& Konrad, 2007). Traditionalism reflects belief in gender-role restrictions such that the female role is that of caregiver and source of marital and familial support, while the male role is primarily that of income provider or "breadwinner" (Brooks \& Bolzendahl, 2004). By contrast, egalitarianism is a flexible view of roles appropriate for women and men, reflecting the belief that both women and men can provide income, as well as engage in caregiving and housework

An earlier version of this article received the Carolyn Dexter Best Paper award from the Eastern Academy of Management International Conference, Bangalore, India, June 2011. The second author is grateful for the support of the Corus Entertainment Chair in Women in Management, Richard Ivey School of Business.

Address correspondence to Lisa T. Stickney, Merrick School of Business, University of Baltimore, 1420 N. Charles St., Baltimore, MD 21202, USA. E-mail: Lstickney@ubalt.edu
(Corrigall \& Konrad, 2007). Previous research has focused nearly exclusively on gender-role attitudes at the individual level (Berrington, Hu, Smith, \& Sturgis, 2008; Ciabattari, 2001; Corrigall \& Konrad, 2007; Fan \& Marini, 2000; Loo \& Thorpe, 1998; Moen, Erickson, \& Dempster-McClain, 1997; Pitt \& Borland, 2008; Wu \& Baer, 1996). However, a few researchers have examined societal-level factors that may be associated with individual-level gender-role attitudes (Banszak \& Plutzer, 1993; Baxter \& Kane, 1995; Motiejunaite \& Kravchenko, 2008; Rosen, 2007; Sjöberg, 2004). The purpose of the present study is to extend that line of research by examining the relationship between social policies and the gender-role attitudes of individuals in 14 countries.

This study differs from the previous research examining societal factors and individual gender-role attitudes in several ways. Among the few studies identified that examine country differences from an institutional perspective, half of these adopted a welfare-state framework and did not directly test for the effects of specific social policies on gender-role attitudes (Baxter \& Kane, 1995; Motiejunaite \& Kravchenko, 2008; Treas \& Widmer, 2000). A key problem with this approach is that using a broad typology of welfare states does not fully predict women's position in society (Orloff, 1993), and within a society, different policies may be capable of influencing behavior and attitudes in different ways. This possibility suggests the need for a finer grained exploration of social policy institutions. The studies that adopted a finer grain stance either examined fewer countries (Banaszak \& Plutzer, 1993; Sjöberg, 2004) or used only one or two policy measures (Banszak \& Plutzer, 1993; Rosen, 2007; Sjöberg, 2004). By contrast, our study includes data from 14 countries at two points in time, and we examine four public policy measures: educational parity, public spending on child care, tax benefits to dual earners, and protected parental leave time.

\section{BACKGROUND AND HYPOTHESES}

Employing an institutional perspective (Brooks \& Bolzendahl, 2004), we suggest that country differences in specific policies are likely to be accompanied by changes in 
individual attitudes about gender roles. Gender roles are the behavioral expectations associated with being male and female (Eagly \& Karau, 2002). These roles in part comprise the norms, values, and culture of society and are often attributed as a causal influence on people's self-concepts, self-presentations, and behaviors (Konrad, 2003; Konrad, Corrigall, Lieb, \& Ritchie, 2000; Konrad, Ritchie, Lieb, \& Corrigall, 2000). Empirically, social policy institutions have been linked to women's and men's job attribute preferences (Corrigall, 2008), maternal employment patterns in 14 countries (Gornick, Meyers \& Ross, 1998), and female employment in Britain (Crompton \& Le Feuvre, 2000), Russia, and Sweden (Motiejunaite \& Kravchenko, 2008). More broadly, Kroska (2002) found that individual differences were not sufficient to overcome the effects of cultural socialization in a study of women's and men's gender-role attitudes.

Social policies reflect and promote a specific set of genderrole attitudes by molding values, norms, and behavior in a particular direction (Alwin, Braun, \& Scott, 1992; Korpi, 2000). Societal institutions can encourage or discourage the development of an egalitarian gender division of labor within the family through the development of incentives or the removal of barriers to particular behaviors (Warren, Fox, \& Pascall, 2009). The typical gender relations produced by a society's institutional arrangements become normalized or viewed as the "normative" model, and gender-role attitudes in the society coalesce around this norm (Motiejunaite \& Kravchenko, 2008). The extent to which societal institutions foster gender restrictions or flexibility in role activities is likely to be associated with the level of traditionalism or egalitarianism in a country (Motiejunaite \& Kravchenko, 2008; Sjöberg, 2004).

Brooks and Bolzendahl (2004) argue that gender-role attitudes are determined by a combination of societal norms and individual experiences. Beyond the normative gender relations dictated by societal-level institutions, each individual family negotiates its own somewhat idiosyncratic set of enacted or "everyday" gender relations. Each person's individual genderrole attitudes result from that individual's personal interests as determined by everyday gender relations within which such people find themselves, combined with their exposure to a variety of different viewpoints and experiences throughout the life course. All of these factors are heavily influenced by societallevel policies, practices, and institutions (Bolzendahl \& Myers, 2004).

An institutional perspective suggests that country differences in policies affect gender relations and gender-role attitudes (Brooks \& Bolzendahl, 2004). To the extent that the societal institutions influencing gender relations differ between countries, we would expect cross-national variation in resulting gender-role attitudes. Four social policies with the potential to influence the experience of gender relations are (a) gender parity in education, (b) public spending on child care, (c) tax benefits to dual earners, and (d) the length of protected parental leaves.
The provision of education to women promotes gender equality and reflects the value of women to society. Women who are afforded the same educational opportunities as men are treated equally by a society that values their potential contributions. Education builds women's human capital, allowing them to command higher earnings in the paid labor force (Brand \& Xie, 2010) and contribute to family income, economically benefiting the entire family. The idea that women and men share the role of income provider is an egalitarian view. As such, individuals in countries that promote the provision of education to women are likely to develop positive attitudes toward this societal service and shift their gender-role attitudes away from traditional views that women with children should stay in the home full-time. Thus, we expect gender parity in education to increase the experience of egalitarian gender relations by removing barriers to women's participation in paid employment.

H1: Individual gender-role attitudes are more egalitarian in countries with greater gender parity in education.

Public expenditure on child care reflects the availability of resources for families with young children to participate in formal day-care services (Organization for Economic Cooperation and Development [OECD], June 30, 2008). The provision of such resources makes continuous participation in the labor force more feasible for parents of young children. The impact is greater for women because they continue to be the primary providers of care to young children in developed countries (Warren, Fox, \& Pascall, 2009). This policy should result in more egalitarian gender-role attitudes among individuals.

With greater public expenditure on child care, women become more capable of generating their own income, which reduces their economic dependency on men (Bianchi, Casper \& Paltola, 1999), and economic independence is associated with greater long-term economic security for women. For men, the policy encourages women's participation in the labor force, which contributes to family income. For both women and men, the public support of child care does not increase and may reduce some of the burden of unpaid domestic labor. These effects are beneficial to both women's and men's interests. As such, individuals in countries with higher levels of public support of child care are likely to develop positive attitudes toward the use of these services and shift their gender-role attitudes toward more egalitarian views that women with children can be active participants in the paid labor force. Thus, we expect public expenditures on child-care services to increase the experience of egalitarian gender relations by supporting women's participation in paid employment.

H2: Individual gender-role attitudes are more egalitarian in countries with larger public expenditures on child care.

Tax policies can either support the traditional family with one main income provider or encourage an egalitarian division of labor in the family by providing incentives for women 
to engage in paid labor (Avdeyeva, 2009). Tax policies vary, such that some countries penalize single-earner families compared to dual-earner families, while in others the reverse is true. Tax policies that are designed so as not to influence the gender-role choices made by families are considered to be gender-neutral (OECD, December 22, 2008). Under joint or family-based taxation systems, the marginal tax rate of the second earner in a family is the same as the marginal rate of the primary earner, and if the tax system is progressive, such a system has possible adverse consequences for dual-earner compared to single-earner couples. Individual tax systems favor dual-earner families because a second earner is taxed less heavily than the primary earner for the additional earnings, so that couples can achieve higher levels of disposable income if both individuals work for pay than if the primary breadwinner simply works more hours (Avdeyeva, 2006). Tax and benefits systems in most OECD countries benefit dual-earner families over traditional families with a single breadwinner (OECD, December 22, 2008).

Compared to the more common model benefitting dualearner over traditional families, tax policies favoring singleearner households should result in a normative model of gender relations where women are less likely to engage in paid labor. Such systems, then, are associated with greater institutional support for traditional gender relations. Compared to women in societies where tax systems benefit dual-earner couples, individuals in societies favoring single-earner families should have less positive attitudes toward female participation in paid labor. In societies where tax systems benefit dual-earner families, individuals are likely to develop more positive attitudes toward women's participation in paid work because their interests are served by the increased disposable income in the family. Thus, we expect countries with tax policies favoring dual-earner families to increase the experience of egalitarian gender relations by supporting women's participation in paid employment.

H3: Individual gender-role attitudes are more egalitarian in countries with tax policies favoring dual-earner families.

The provision of parental leave allows women and men to take a leave of absence from work upon the birth of a child without the threat of job loss. Parental leave systems can include maternity leave, paternity leave, and parental leave (which protects employed parents regardless of gender). On average, OECD countries provide 18 weeks of paid maternity leave and 2 weeks of paid paternity leave (OECD, 29 July 2009). Countries differ in the total amount of leave time parents may take without job loss by combining maternity, paternity, and parental leave. Countries also differ in how generous their leave-related family payments are.

In most countries, parents can decide how to divide the amount of leave between a child's mother and father. A few countries, such as Sweden and Iceland, pursue gender equality by introducing father quotas in parental leave systems, which require fathers to take part of the parental leave or else lose the benefit entirely (Motiejunaite \& Kravchenko, 2008; Warren, Fox, \& Pascall, 2009). The provision of a larger amount of leave and more income during the leave provides families with greater flexibility in their choices of gender-role activities for both women and men.

Theoretically, parental leave is thought to increase the ability of mothers to return to work after the arrival of children, thereby increasing their labor-force attachment (Gornick, Meyers, \& Ross, 1997). In practice, however, the bulk of parental leave time is taken by mothers, particularly in the absence of father quotas. In some countries, protected leave times last as long as 156 weeks for each child (OECD, July 1, 2010), such that women with multiple children spend several years out of the labor force. Thus, long parental leave times encourage women to forgo paid work, reducing their career development and reinforcing the traditional gender division of labor in the home (Avdeyeva, 2006; Hemmings, 2007). As such, very long parental leave times reflect an institutional sanctioning of the view that mothers with young children should not work (Avdeyeva, 2009).

It is likely that the relationship between parental leave times and gender-role attitudes is curvilinear. Countries with no leave or very short leave times are likely to hold the traditional view that a woman's primary role is in the family. In the traditional view, women do not care as much about continuing their careers after their children are born, so that protecting women's jobs during a substantial parental leave is unnecessary. Given that countries with very long leaves encourage women to withdraw from the labor force for several years, countries with mediumlength parental leave times are most likely to encourage women to participate in both paid work and family, promoting egalitarian beliefs. Thus, we hypothesize that the relationship between parental leave times and gender-role attitudes is in the form of an inverted U.

H4: The relationship between individual gender-role attitudes and parental leave times is an inverted $\mathrm{U}$, such that individuals in countries with the shortest and longest leaves are most traditional, while those in countries with mediumlength leaves are most egalitarian.

In sum, consistent with an institutional perspective, we expect that people's gender-role attitudes will become more egalitarian when societies enact more egalitarian policies. Hence, gender parity in education, tax policies favoring dualearner families, and public expenditures on child care are likely to be positively associated with egalitarian gender-role attitudes for both women and men. Parental leave times that are too short or too long are less likely to generate egalitarian attitudes as these enable and enforce women's traditional homemaking role. As such, mid-length parental leave times are expected to be associated with the most egalitarian gender-role views. 


\section{METHOD}

The data for the empirical analyses came from the International Social Survey Program (ISSP), a continuing annual cross-national research program currently involving 45 nations. Annual topics are selected; then, after pretesting and final approval by the ISSP, the questionnaire is administered in all participating countries. Questions are drafted in British English and translated into the other languages. Participants are required to provide nationally representative samples of the adult population in their country and must conform to ISSP principles (ISSP Working Principles, 2010). Specific survey methods may vary by country, and data are often collected as part of a larger national social survey. For example, in Great Britain the data were collected as part of the British Social Attitudes Survey. The sample was a stratified random sample based on postal codes, and surveys were administered through a self-completed questionnaire given after completing a face-to-face interview. By contrast, in Australia, the sample was a simple random sample drawn from compulsory election rolls and conducted by mail. In the Czech Republic, the data were obtained through face-to-face interviews based on a multistage random sample, and in the United States, data were collected as a supplement to the General Social Survey (Family and Changing Gender Roles Codebook, 1994, 2002).

The data on Family and Changing Gender Roles were collected in 24 countries in 1994 and 35 countries in 2002. However, complete data were only available for 14 countries in both 1994 and 2002. The numbers of respondents for which we had complete data by country and year are presented in Table 1. It should be noted that the individuals surveyed for the 1994 and 2002 cross-sections were different, so that our data source was not longitudinal.

\section{Measures}

\section{Dependent Variable}

To obtain our measure of gender egalitarianism, we averaged the responses to four items assessing beliefs regarding appropriate roles for women and men. The selection of these items was based on previous research identifying the items as being most comparable cross-nationally (Braun, 1998). The items were "A pre-school child is likely to suffer if his or her mother works"; "All in all, family life suffers when the woman has a full-time job"; "A job is all right, but what most women really want is a home and children"; and "A husband's job is to earn money; a wife's job is to look after the home and family." The items were scored on a 5-point scale ranging from 1 (strongly agree) to 5 (strongly disagree). Higher scores indicate more egalitarian gender-role attitudes. We factor analyzed the items in both the 1994 and 2002 data sets, and each produced a one-factor solution using the four items. The measure showed adequate reliability at both points in time $(1994, \alpha=.79 ; 2002$, $\alpha=.77)$.

\section{Independent Variables}

Public policy data were obtained from the United Nations (UN) and the Organization for Economic Cooperation and Development (OECD). Educational parity was provided by the UN (UNESCO Institute for Statistics Data Centre, 2007) and reflects the ratio of girls to boys in secondary education. The public policy data obtained from the OECD were public spending on child care, parental leave time, and tax benefits to single earners. Public spending on child care includes expenditures on child care and preprimary education expressed as a percentage of gross domestic product (GDP; OECD, June 30, 2008). Parental leave time is the number of weeks of job-protected leave available to parents (OECD, July 29, 2009). Tax benefits to single earners measures the extent to which a tax system benefits single-earner over dual-earner families. This measure is represented by the difference between taxes paid by a single breadwinner and two equal earners earning the same amount (based upon an income level that is $133 \%$ of the national average). In this measure, gender-neutrality would be represented by a value of zero. Positive values indicate a tax system that favors single-earner families, and negative numbers indicate a tax system that favors dual-earner families (OECD, December 22, 2008).

We used educational parity data from 1991 and 2002, public spending on child care from 2005, tax policy from 2006, and parental leave times from 2006. We sought national policy information from 1994 and 2002 and were informed that those data are unavailable. However, the 2006-2008 data reflect the ordering of the countries regarding the egalitarianism of their gender relations policies. This ordering is unlikely to have changed much between 1994 and 2008. The most traditional countries probably remained more traditional than the more egalitarian countries, even if all countries changed their policies slightly over this period of time. Furthermore, the basic approach to family policy taken by each country has not changed during this time frame. Korpi (2000) identifies three basic family policy stances, specifically, support of single-earner families, support of dual-earner families, and a liberal or market-oriented approach. Korpi's classification system continues to be used to categorize countries by their family policies (e.g., Sjöberg, 2010), which supports our premise that the basic public policy foundations in these countries has not changed dramatically during this time period.

\section{Controls}

We controlled for a number of variables that previous research has shown to be related to individual gender-role attitudes. These included gender $(1=$ male, $2=$ female), age (in years $)$, married or living as married $(1=$ yes, $0=$ no), education, has had a child ( $1=$ yes, $0=$ no), and full-time employed ( $1=$ yes, $0=$ no). Within each country, education was recoded into one of four possible categories $(1=$ below secondary education, 2 = secondary education complete, $3=$ postsecondary or technical education, $4=$ college or university degree). 


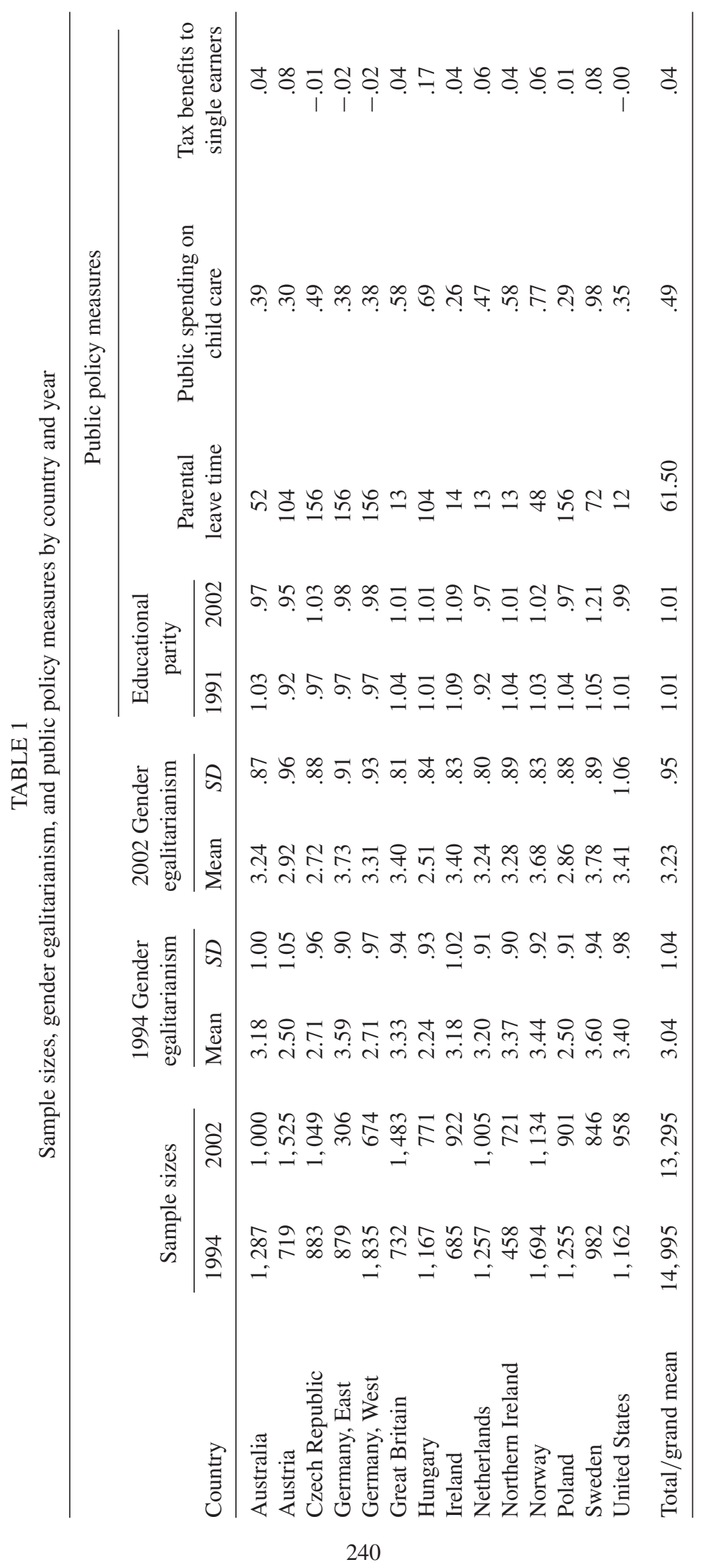


Descriptive statistics and correlations for all measures included in the 1994 and 2002 analyses are presented in Table 2.

\section{Analyses}

Given the nested nature (individuals within countries) of the data, we tested our hypotheses with hierarchical linear modeling (HLM). HLM is a model-building technique that allows for the analysis of multilevel data. It recognizes that individuals nested within groups may be more similar to each other than individuals from different groups by simultaneously accounting for variances and covariances-both within and between levels of analysis (Raudenbush \& Bryk, 2002).

HLM begins with a null or unconditioned model that contains only the dependent variable and group (country) assignments. The null model for gender egalitarianism, our dependent variable, was significant in both the $1994\left(\chi^{2}=3110.80\right.$, $p=.00)$ and $2002\left(\chi^{2}=2049.25, p=.00\right)$ data sets, confirming that between-country variance comprises a significant portion of the total variance, and that the use of HLM is warranted.

Model building in HLM continued with the creation of the full model. In the full model, the predictors were centered on their grand means before inclusion. Grand-mean centering is preferred because it produces results equivalent to the uncentered metric and reduces potential collinearity (Hofmann \& Gavin, 1998). In all models, the dependent variable was gender egalitarianism. At the individual level, we entered our control variables: gender, age, married, education, has had a child, and full-time employed. Educational parity, parental leave time, parental leave time squared, public spending on child care, and tax benefits to single earners were entered at the country level.

\section{RESULTS}

\section{Country Differences}

We began our analyses by exploring intercountry differences in the social policy and gender-role attitude measures (see Table 1). An examination of the social policy variables shows that there are differences between countries. However, the differences are minimal for educational parity. In 1994, on average, there is parity in secondary education (mean $=1.01$, $S D=0.05$ ) among the 14 countries in our data set. The ratios of females to males in secondary education ranged from a low of 0.92 in Austria and the Netherlands to a high of 1.09 in Ireland. In 2002, on average, there also appears to be parity in secondary education (mean $=1.01, S D=0.07$ ); however, there is more variance than in 1994, most likely due to the high ratio in Sweden, where approximately $21 \%$ more females than males were enrolled in secondary education. At the low end of the range was Austria, which educated more males than females (0.95).

There was considerably more variance in the other social policy measures. The average parental leave time across countries was 76.57 weeks $(S D=61.31)$ of protected leave. The number of weeks of parental leave ranged from lows of 12 (United States) and 13 weeks (Great Britain, the Netherlands, and Northern Ireland) to a high 156 weeks (Czech Republic, Germany, and Poland). As for public spending on child care, it too varied somewhat across countries. The average spent on child care and preprimary education was $0.49 \%(S D=.21)$ of GDP, which ranged from a low of $0.26 \%$ in Ireland to a high of $0.98 \%$ in Sweden. Finally, on average, taxation policies in the countries in our data sets generally favored single earners (mean $=0.04, S D=0.05$ ), but the Czech Republic and the former East and West Germany had tax policies that slightly favored dual earners. The tax system in the United States was closest to neutral, with the difference between the taxes paid by single and dual earners being $-0.009 \%$. The remaining countries had policies that favored single earners, with Hungary's differential of $17 \%$ being the largest.

Analyses of variance (ANOVAs) examining mean genderrole attitudes by country revealed significant differences between countries in both data sets: $1994, F_{(13,14981)}=238.62$, $p<.001 ; 2002, F_{(13,13281)}=156.90, p<.001$. In 1994, the most traditional gender-role attitudes were found in Hungary, followed by followed Austria and Poland. By contrast, individuals in the former East Germany and Sweden held most egalitarian gender-role attitudes. In 2002, the rankings were fairly similar. Individuals in Hungary stood alone as the most traditional. This was followed by the Czech Republic and Poland, whose residents' gender-role attitudes were fairly traditional. At the other end of the spectrum, Sweden, the former East Germany, and Norway had the designation of being most egalitarian.

\section{Hypothesis Testing}

Table 3 shows the results of the HLM analyses examining gender-role attitudes in 1994 and 2002. H1 predicted that gender-role attitudes would be more egalitarian in countries greater gender parity in education. As depicted in Table 3, the nonsignificant coefficients for educational parity in both the 1994 and 2002 models indicate no support for this hypothesis.

In our second hypothesis, we expected that individuals would hold more egalitarian attitudes in countries with larger expenditures on child care. Although the coefficients for public spending on child care were in the predicted direction in both the 1994 and 2002 analyses (see Table 3), they did not achieve significance. Thus, $\mathrm{H} 2$ was not supported.

H3 anticipated a relationship between tax policies and individual gender-role attitudes, such that more egalitarian attitudes would be found in countries with tax policies favoring dual earners. The coefficients (see Table 3 ) on tax benefits to single earners in the $1994(\gamma=-4.90, S E=1.83, p<.05)$ and 2002 $(\gamma=-3.36, S E=1.37, p<.05)$ analyses were both significant and negative, indicating full support for this prediction.

$\mathrm{H} 4$ predicted the relationship between parental leave time and individual gender-role attitudes would show an inverted-U 


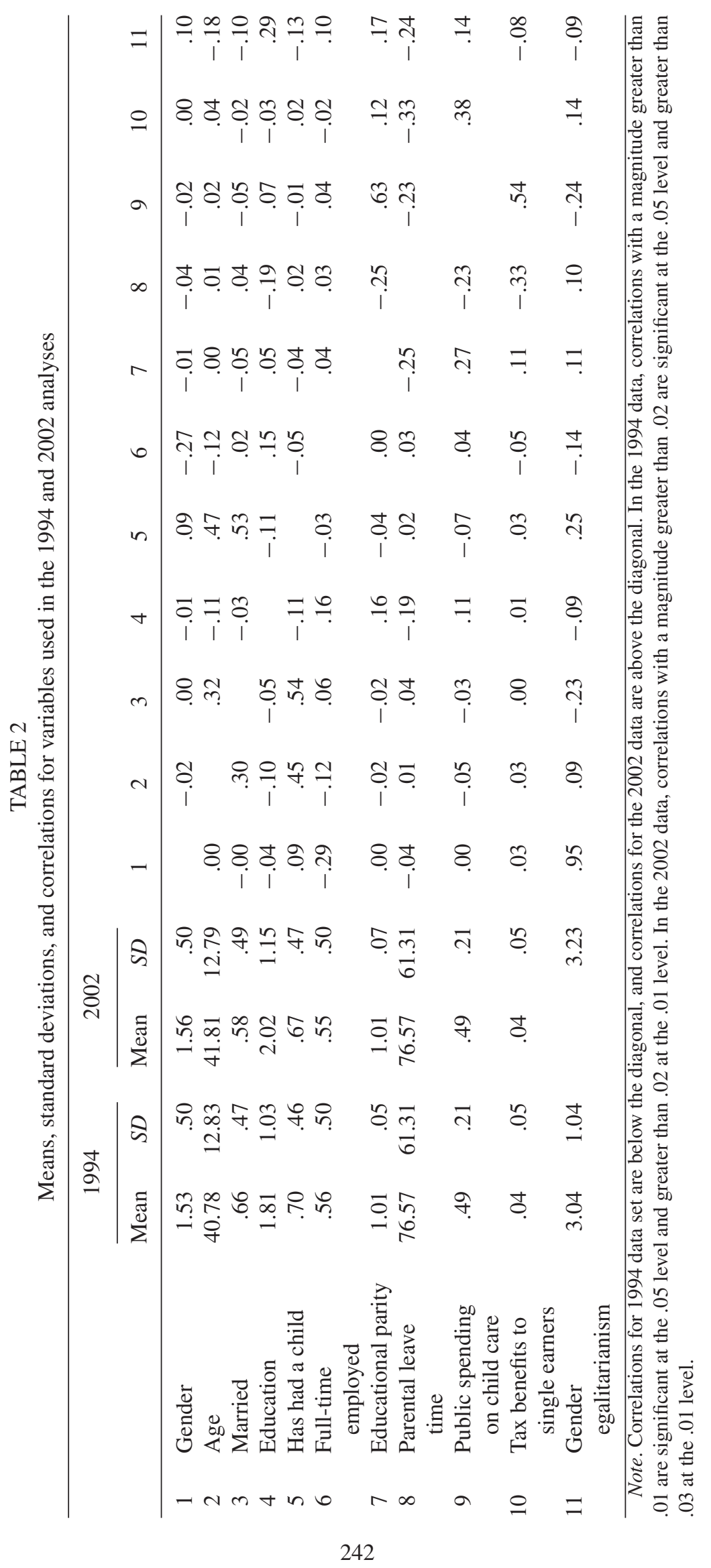


TABLE 3

Results of HLM analyses predicting work and family gender egalitarianism

\begin{tabular}{lcccr}
\hline & \multicolumn{2}{c}{1994} & & 2002 \\
\cline { 2 - 3 } & Coefficient & $S E$ & Coefficient & $S E$ \\
\hline Individual level & & & \\
Intercept & $3.06957^{* * *}$ & .071 & $3.25777^{* * *}$ & .053 \\
Gender & $.25486^{* * *}$ & .015 & $.26180^{* * *}$ & .015 \\
Age & $-.01530^{* * *}$ & .001 & $-.00943^{* * *}$ & .001 \\
Married & -.01370 & .019 & $.17027^{* * *}$ & .017 \\
Education & $.17695^{* * *}$ & .008 & -.03355 & .007 \\
Has had a child & $-.05908^{* *}$ & .021 & $.17628^{* * *}$ & .020 \\
Full-time employed & $.18172^{* * *}$ & .016 & 1.62485 & .016 \\
Country level & .30354 & & .36192 & 1.115 \\
Educational parity & .82852 & 1.660 & $-3.36098^{*}$ & .394 \\
Public spending on child care & $-4.90085^{*}$ & .419 & .00187 & 1.368 \\
Tax benefits to single earners & -.00103 & .023 & $-.00004^{* *}$ & .001 \\
Parental leave time & -.00003 & .000 & .04 & .000 \\
Parental leave time squared & & & .70 & $385.85_{(8)}^{* * *}$ \\
Final estimate of variance: & .07 & & \\
Individual-level variance & .80 & & & \\
Country-level variance & $922.73_{(8)}^{* * *}$ & & & \\
Model $\chi^{2}(d f)$ & & & & \\
\hline
\end{tabular}

${ }^{*} p<.05 .{ }^{* *} p<.01{ }^{* * *} p<.001$.

shape. The prediction was that individual gender-role attitudes would be most traditional in countries with very low and very high parental leave times and most egalitarian among countries with mid-length parental leaves. This relationship was tested by including a quadratic term (parental leave time squared) in the models. The results of these analyses can be seen in Table 3. The coefficient on parental leave time squared in the 1994 model was not significant; however, it was significant in the 2002 model $(\gamma=-.00004, S E=.000, p<.01)$. A graph of the relationship between parental leave times and gender egalitarianism for the 2002 data produced an invertedU shape (see Figure 1). The turning point from egalitarianism to traditionalism in gender-role attitudes occurred at approximately 31 weeks of parental leave time; however, the steepest portion of the shift towards traditionalism occurred at approximately 75 weeks of parental leave time. Thus, H4 was partially supported.

\section{DISCUSSION}

This research shows some significant associations between national policies at the country level and gender-role attitudes at the individual level and provides support for an institutional explanation (Bolzendahl \& Myers, 2004) of individual gender-role attitudes. In this framework, some national policies and practices can influence the typical or normative view of appropriate gender roles (Motiejunaite \& Kravchenko, 2008),

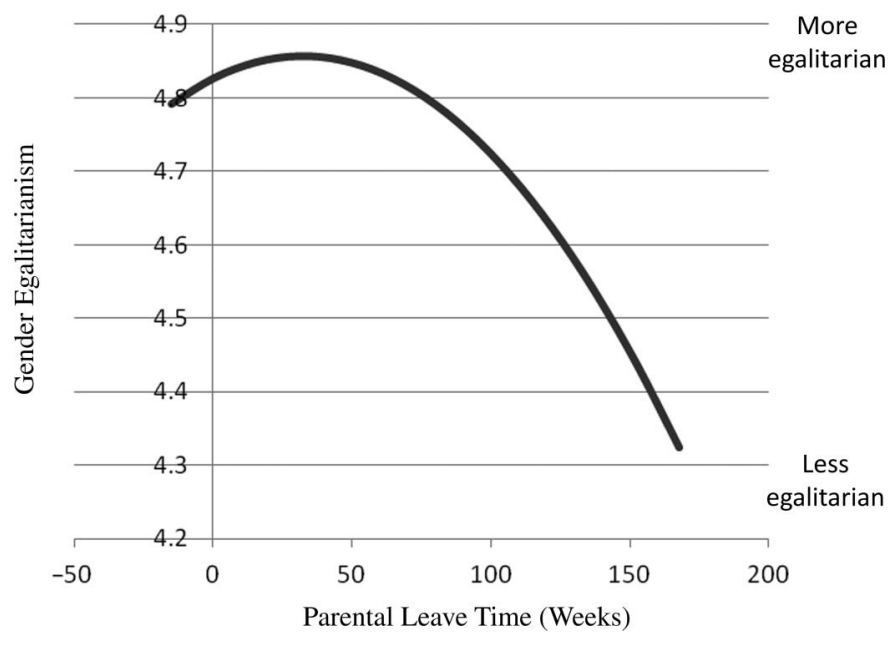

FIG. 1. Relationship between parental leave time and egalitarianism in gender-role attitudes in 2002.

first, by explicitly legitimizing a particular set of gender relations, and second, by creating a set of incentives and barriers that channel people's behaviors to fit the normative model (Warren et al., 2009). Within a society's normative model, individual families negotiate how they actually fulfill the roles of homemaker and income provider. The everyday gender relations people experience as a result of their role negotiations determine their personal interests (Brooks \& Bolzendahl, 
2004). Gender-role attitudes result from a combination of the societal-level discourse regarding the legitimacy of particular gender relations, interactions with other members of the society discussing their views and experiences, and one's personal interests resulting from role occupancy.

Public spending on child care was not associated with individual gender-role attitudes. We expected that the effect of public spending on child care would reduce barriers to mothers' participation in paid employment, thereby creating greater flexibility in society's normative model of gender relations, but we did not find any such effect. This may have occurred because public spending on child care is entrenched in society, its provision an expectation, viewed by individuals as a societal right. If so, it would be likely to lose its power to influence behavior and attitudes. Testing the extent that individuals become habituated to expect the provision of public spending on child care is a matter for future research.

As predicted, tax supports for dual-earner families compared to single-earner families were associated with more egalitarian gender-role attitudes in both 1994 and 2002. This finding supports our contention that tax policy supporting dual-earner families results in greater labor-force participation of both parents in families with children, rather than in a single earner increasing the number of hours worked. As such, tax policies may be an effective method to reinforce societal norms of gender relations.

Also as predicted, the relationship between parental leave time and gender-role attitudes was curvilinear in 2002 but not in 1994. One possible reason that we found an effect in 2002 but not in 1994 might involve the fact that in our data, individuals in 2002 were found to be more egalitarian than their 1994 counterparts in the same 14 countries. The bulk of parental leaves are taken by mothers, rather than fathers (Hemmings, 2007). Very short leave times push mothers out of the labor force due to job loss, while very long parental leaves incentivize mothers to withdraw from paid work for several years (Avdeyeva, 2009). As gender-role attitudes become more egalitarian with each new cohort of individuals (Treas $\&$ Widmer, 2000), the effect of very long leaves encouraging withdrawal from the labor force would be stronger for those in later years than in earlier years because leaving the labor force for an extended period is contrary to individuals' egalitarian gender-role beliefs. Future research would be needed to test this specifically.

In 2002, we found an inverted U-shaped relationship between parental leave times and gender egalitarianism, which supports the reasoning that the mid-length leaves maximize women's ability to combine career and family are associated with the most egalitarian gender-role attitudes. Both the lowest and highest levels of parental leave were associated with more traditional gender-role attitudes. In our data, the turning point in gender-role attitudes occurred after approximately 31 weeks of protected leave. However, leaves longer than 75 weeks were most strongly associated with traditional gender-role attitudes. Thus, societies that wish to promote egalitarianism in gender-role attitudes could do so with protected parental leaves of approximately 31 weeks in length, while those wishing to promote traditionalism in gender-role attitudes should consider protected parental leave times of longer than 75 weeks. Whether the inverted-U shape of this relationship or the time frames we observed would hold in other countries is an interesting question and a matter for future research.

Unrelated to gender-role attitudes was gender parity in secondary education. This is likely because of little variance in the ratio of girls to boys in secondary education. On average, in both years, the proportion of girls and boys in secondary education was nearly equal. Inclusion of countries with greater gender disparity in the provision of education is necessary to conduct a sufficiently powerful test of the relationship between country-level educational parity and individual gender-role attitudes.

\section{Limitations}

Like all research, this study has its limitations. The use of cross-sectional data limits our ability to draw causal inferences from our findings. Although we used nationally representative data from 14 societies at two points in time, the two points in time were 10 and 18 years ago. Despite their age, we believe these data have value because the focus of this research involves gender-role attitudes. Although gender-role attitudes have changed during the past 25 years, recent research has found the rate of change to be been slow (Vespa, 2009). A better test of these hypotheses would involve more current data and a truly longitudinal data set employing large, representative samples from multiple countries. This is a matter for future research, however, because to our knowledge, such a data set does not exist, and the ISSP data provided a unique opportunity to examine gender-role attitudes in a multinational environment at two points in time.

Another limitation of this database is the failure to assess the presence of children in the household and their ages. Too few of the ISSP country data sets included such a measure to allow us to test the possible effects of the presence of children on gender differences in gender-role attitudes. However, the ISSP has several questions that establish whether the respondents have ever had children, and one of these was used as a control in our analyses. Future research should include the actual number of children in the household and their ages.

Our measures were limited to the questions that had been asked in the ISSP studies, and as such did not include important gender-role issues such as attitudes toward women's participation as leaders in government and business organizations or women's participation in entrepreneurship. The ISSP survey did not ask questions about men's participation in domestic labor or child care. Because most research has examined only women's role in paid work and the family, there are many gaps in our knowledge of the full complexity of gender-role attitudes. 


\section{Conclusions}

Gender-role attitudes show predictable associations with national policies instituting tax benefits to dual earners. However, the relationship between parental leave systems and individual gender-role attitudes is more complicated. Very short and very long leaves are related to traditionalism, while middlelength leaves are related to more egalitarian attitudes toward gender roles. These results provide support for an institutional perspective on individual gender-role attitudes, whereby, individuals modify their attitudes to match the norms of society as well as their personal experiences.

\section{REFERENCES}

Alwin, D. F., Braun, M., \& Scott, J. (1992). The separation of work and the family: Attitudes towards women's labour-force participation in Germany, Great Britain, and the United States. European Sociological Review, 8, 13-37.

Avdeyeva, O. (2006). In support of mothers' employment: Limits to policy convergence in the EU? International Journal of Social Welfare, 15, 37-49.

Avdeyeva, O. (2009, April). Social policy reforms in Hungary: Towards a dualearner model? Paper presented at the EUSA 11th Biennial International Conference, Los Angeles, CA. Retrieved from http://www.unc.edu/euce/ eusa2009/papers/avdeyeva_12E.pdf

Banaszak, L. A., \& Plutzer, E. (1993). Contextual determinants of feminist attitudes: National and subnational influences in western Europe. American Political Science Review, 87, 145-157.

Baxter, J., \& Kane, E. W. (1995). Dependence and independence. A crossnational analysis of gender inequality and gender attitudes. Gender \& Society, 9, 193-215.

Berrington, A., Hu, Y., Smith, P. W. F., \& Sturgis, P. (2008). A graphical chain model for reciprocal relationships between women's gender role attitudes and labour force participation. Journal of the Royal Statistical Society: Series A, Statistics in Society, 171, 89-108.

Bianchi, S. M., Casper, L. M., \& Peltola, P. K. (1999). A cross-national look at married women's earnings dependency. Gender Issues, 17, 3-33.

Bolzendahl, C. I., \& Myers, D. J. (2004). Feminist attitudes and support for gender equality: Opinion change in women and men, 1974-1998. Social Forces, 83, 759-789.

Brand, J. E., \& Xie, Y. (2010). Who benefits most from college? Evidence for negative selection in heterogeneous economic returns to higher education. American Sociological Review, 75(2), 273-302.

Braun, M. (1998). Gender roles. In J. W. van Deth (Ed.), Comparative politics: The problem of equivalence (pp. 111-134). New York, NY: Routledge.

Brooks, C., \& Bolzendahl, C. (2004). The transformation of US gender role attitudes: Cohort replacement, social-structural change, and ideological learning. Social Science Research, 33, 106-133.

Ciabattari, T. (2001). Changes in men's conservative gender ideologies: Cohort and period influences. Gender \& Society, 15, 574-591.

Corrigall, E. A. (2008). Welfare states, families, job attribute preferences, and work. Cross Cultural Management, 15, 144-161.

Corrigall, E. A., \& Konrad, A. M. (2007). Gender role attitudes and careers: A longitudinal study. Sex Roles, 56, 847-855.

Crompton, R. \& Le Feuvre, N. (2000). Gender, family and employment in comparative perspective: The realities and representations of equal opportunities in Britain and France. Journal of European Social Policy, 10, 334-348.

Eagly, A. H., \& Karau, S. J. (2002). Role congruity theory of prejudice toward female leaders. Psychological Review, 109, 573-598.

Family and changing gender roles codebook. (1994). Koeln, Germany: Zentralarchiv fuer Empirische Sozialforschung.

Family and changing gender roles codebook. (2002). Koeln, Germany: Zentralarchiv fuer Empirische Sozialforschung.

Fan, P.-L., \& Marini, M. M. (2000). Influences on gender-role attitudes during the transition to adulthood. Social Science Research, 29, 258-283.
Gornick, J. C., Meyers, M. K., \& Ross, K. E. (1998). Public policies and the employment of mothers: A cross-national study. Social Science Quarterly, 79, 35-54.

Hemmings, P. (2007). Family policy in Hungary: How to improve the reconciliation between work and family? OECD Economics Department Working Papers, No. 566, OECD Publishing. Retrieved from http://www.eric.ed.gov/ PDFS/ED503990.pdf

Hofmann, D. A., \& Gavin, M. B. (1998). Centering decisions in hierarchical linear models: Implications for research in organizations. Journal of Management, 24, 623-641.

ISSP working principles. (2010). Retrieved from http://www.issp.org/uploads/ editor_uploads/files/isspchar.pdf

Konrad, A. M. (2003). Family demands and job attribute preferences: A 4-year longitudinal study of women and men. Sex Roles, 49(1/2), 35-46.

Konrad, A. M., Corrigall, E., Lieb, P., \& Ritchie, J. E., Jr. (2000). Sex differences in job attribute preferences among managers and business students. Group and Organization Management, 25, 108-131.

Konrad, A. M., Ritchie, J. E., Jr., Leib, P., \& Corrigall, E. (2000). Sex differences and similarities in job attribute preferences: A meta-analysis. Psychological Bulletin, 126, 593-641.

Korpi, W. (2000). Faces of inequality: Gender, class, and patterns of inequalities in different types of welfare states. Social Politics, 7, 127-191.

Kroska, A. (2002). Does gender ideology matter? Examining the relationship between gender ideology and self- and partner-meanings. Social Psychology Quarterly, 65, 248-265.

Loo, R., \& Thorpe, K. (1998). Attitudes toward women's roles in society: A replication after 20 years. Sex Roles, 39, 903-912.

Lye, D. N., \& Waldron, I. (1997). Attitudes toward cohabitation, family, and gender roles: Relationships to values and political ideology. Sociological Perspectives, 40, 199-225.

Moen, P., Erickson, M. A., \& Dempster-McClain, D. (1997). Their mother's daughters? The intergenerational transmission of gender attitudes in a world of changing roles. Journal of Marriage and Family, 59, 281-293.

Motiejunaite, A., \& Kravchenko, Z. (2008). Family policy, employment and gender-role attitudes: A comparative analysis of Russia and Sweden. Journal of European Social Policy, 18, 38-49.

Organization for Economic Cooperation and Development. (2010, July 1). Key characteristics of parental leave systems (PF2.1). Retrieved from www.oecd. org/els/social/family/database

Organization for Economic Cooperation and Development. (2009, July 29). Key characteristics of parental leave systems (PF7). OECD Family Database. Retrieved from www.oecd.org/els/social/family/database

Organization for Economic Cooperation and Development. (2008, December 22). Neutrality of tax/benefit systems (PF4). OECD Family Database. Retrieved from www.oecd.org/els/social/family/database

Organization for Economic Cooperation and Development. (2008, June 30). Public spending on childcare and early education (PF10). OECD Family Database. Retrieved from www.oecd.org/els/social/family/database

Orloff, A. S. (1993). Gender and the social rights of citizenship: The comparative analysis of state policies and gender relations. American Sociological Review, 58, 303-328.

Pitt, R. N., \& Borland, E. (2008). Bachelorhood and men's attitudes about gender roles. Journal of Men's Studies, 16, 140-158.

Raudenbush, S. W., \& Bryk, A. S. (2002). Hierarchical linear models: Applications and data analysis methods (2nd ed.). Thousand Oaks, CA: Sage Publications.

Rosen, J. (2007). Attitudes towards gender roles in the public sphere: An individual and contextual level analysis in 39 countries. Paper presented at the annual meeting of the American Sociological Association. Retrieved from http://search.ebscohost.com/login.aspx?direct $=$ true $\& \mathrm{db}=$ sih $\& A N=34595491 \&$ site $=$ ehost-live

Sjöberg, O. (2004). The role of family policy institutions in explaining genderrole attitudes: A comparative multilevel analysis of thirteen industrialized countries. Journal of European Social Policy, 14, 107-123.

Sjöberg, O. (2010). Ambivalent attitudes, contradictory institutions: Ambivalence in gender-role attitudes in comparative perspective. International Journal of Comparative Sociology, 51, 33-57. 
Stickney, L. T., \& Konrad, A. M. (2007). Gender-role attitudes and earnings: A multinational study of married women and men. Sex Roles, 57, 801-811.

Treas, J., \& Widmer, E. D. (2000). Married women's employment over the life course: Attitudes in cross-national perspective. Social Forces, 78(4), $1409-1436$.

UNESCO Institute for Statistics Data Centre. (2007). UNESCO Institute for Statistics Data Centre custom tables. Retrieved from http://stats.uis.unesco. org/unesco/TableViewer/document.aspx ?ReportId $=136 \& I F \_L a n g u a g e=$ eng\&BR_Topic $=0$

Vespa, J. (2009). Gender ideology construction: A life course and intersectional approach. Gender \& Society, 23, 363-387.

Warren, T., Fox, E., \& Pascall, G. (2009). Innovative social policies: Implications for work-life balance among low-waged women in England. Gender, Work \& Organization, 16, 126-150.

Wu, Z., \& Baer, D. E. (1996). Attitudes toward family and gender roles: A comparison of English and French Canadian women. Journal of Comparative Family Studies, 27, 437-452.

\section{ABOUT THE AUTHORS}

Lisa T. Stickney is Assistant Professor of Management in the Merrick School of Business at the University of Baltimore. Professor Stickney's current work focuses on gender-role attitudes, emotions in organizations, particularly anger, and management pedagogy. She may be reached at Lstickney@ubalt.edu.

Alison M. Konrad joined the Richard Ivey School of Business, The University of Western Ontario, in 2003 as Professor of Organizational Behaviour and holder of the Corus Entertainment Chair in Women in Management. Professor Konrad's current work focuses on organizational values, diversity initiatives, and making workplaces more inclusive. She may be reached at akonrad@ivey.uwo.ca. 